\title{
An analysis of college teachers' awareness about conducting action research for effective teaching
}

\author{
Saima Naz, Sufiana Khatoon Malik \\ Education Department, National University of Modern Languages (NUML), Islamabad, Pakistan \\ Email address: \\ drsmalik2001@yahoo.com (S. K. Malik), sufiana.khatoon@numl.edu.pk (S. K. Malik)
}

\section{To cite this article:}

Saima Naz, Sufiana Khatoon Malik. An Analysis of College Teachers' Awareness about Conducting Action Research for Effective Teaching. International Journal of Secondary Education. Vol. 2, No. 1, 2014, pp. 7-10. doi: 10.11648/j.ijsedu.20140201.12

\begin{abstract}
The present research is a conceptual research which addresses college teachers of awareness about the concept and procedure of action research in public sector colleges in Pakistan. It was assumed that college teachers of public sector are not aware about the concept and procedure of action research. Related literature was reviewed in order to generate few descriptive type questions for data collection. Informal interviews and structured interview were held in order to collect data from the staff members. Forty college teachers, including experienced, senior and junior, were selected as sample from different colleges of Rawalpindi Division. The researcher analyzed data in qualitative form. Findings of the study depicts that college teachers are not familiar with technical concept and procedure of action research. However, they do conduct action research regular basis in their class rooms for bringing quality in teaching and learning. Based on findings it was suggested that college teachers might be provided training in how to conduct action research in order to make their teaching effective to get full benefits of action research.
\end{abstract}

Keywords: College, Teachers, Awareness, Action Research, Effective Teaching, Training

\section{Introduction}

A teacher observes behavior of the students and develops insight among them. A reflective teacher speculates and fined out problems of the students, he modifies his teaching techniques and grip the situation by technical evaluation methodologies. Sometimes his techniques work and sometimes they are failed, this is called action research.

Action research is commonly known as participatory action research, community based study, cooperative enquiry, and action science of action learning. It is generally used for improvement of conditions and practices in the rang of a particular field. When action research is conducted in the field of education; basic purpose is to enhance the working environment and give more space to teaching and learning. Action research needs careful planning, deep observations, sharp listening skills, evaluation and critical reflection. Action research is a reliable source for generating solutions of the practical problems.

Research is a natural part of teaching (Christine Miller, 2007). As miller described action research as a natural part of teaching, he broadens its spectrum. During every day teaching the teacher naturally grip on the problems or gaps of teaching and learning and sometimes this process continue unconsciously specially if one is an experienced teacher. Teachers using action research minimizes the classroom problems and enhances learning capacity of the students. Moreover action research helps a teacher to maintain discipline and avoids disruptive behavior.

"For me it is really a quest for life, and to create what I call living knowledge- knowledge which is valid for the people with whom I work and for myself ( Marja Liisa Swantiz, in Reason and Brandburg 2001:1).

As Marja expresses his views about action research are very appealing. A teacher is creating living knowledge by solving the problems practically and these solutions are becoming part of knowledge as they are useful for the practitioners and nest generations. So class rooms are those factories from where products are manufactures without any fault as teachers has sorted out all the faults and give them proper finishing.

Sagor (2000) identifies three major purposes of action research. First is building the reflective practitioners, second one is making progress and third is building a professional culture in educational arena. By conducting action research a teacher practice such techniques which were in raw form with teacher. After utilization in real classroom settings, these are proved useful or useless, in 
result one get progress and a professional culture is developed in the educational organizations. This ultimately benefits the system of education.

As John Elliot cited in ( Understanding Action Research, MALT 2002-2B) suggested that action research is " concerned with the everyday practical problems experienced by the teachers, rather than the theoretical problems, defined by pure teachers within a discipline of knowledge." Action research in education is a collaborative activity and it works for development of concept of team work in teaching, now teaching is no more an isolated effort.

Action research is cyclic in nature, as its models presented by Stringer's look-think-act approach, Kemmis and Mc Taggart Model and many more revealed this fact clearly.

Carrie Eunyoung Hong 2011 reports Reflection is a significant component of self-study and action research (Mills, 2003). According o him action research is a critical inquiry and one is reflective when using it. A reflective teacher considers all aspects of teaching and learning in order to evaluate standard of teaching. Teaching is a multidimensional task in which complex ecologies are involved like individual, social, cultural and political. Teaching effect all ecologies so it becomes essential to conduct action research in all aspects of teaching. Students are complete individuals and they belong to different social and cultural setup, that is why their learning outcomes are also unique. It is another important phenomena that performance of the teacher should be measured in objective way, in this regard it a paradigm shift now that in spite of using different evaluation techniques for performance of teacher, teacher herself reflect and research on the aspects of her performance and take measures to fill the gap. (Alsop, Dippo, \& Zandvliet, 2007), in this way a teacher become change agent and decision maker.

\section{Research Objectives}

The present study was carried out to achieve the following objectives:

1 To explore teacher's awareness about concept of action research.

2 To find out how teachers use action research for quality instruction.

\section{Research Questions}

1 What are teachers' views about concept of action research?

2 How action research conducted by teachers effect instruction?

\section{Methodology and Sampling}

Present study was conducted to explore the fact that what is the worth of action research in college level teaching in public sector female college faculty members. The study was qualitative in nature. Related literature was studied by the researcher in order to determine the suitable tool for data collection. The literature helps the researcher to form few questions to investigate about action research and its usefulness for college faculty members. All female college faculty members in Rawalpindi division were selected as population. By using cluster random sampling technique, five colleges were selected as clusters. Randomly forty faculty members were selected as sample. Eight members from each college were selected.

\section{Data Collection Tool}

Informal interviews and structured interview were held in order to collect data from the staff members. Every one shared their views about use of action research and its value for teaching and learning process. Some faculty members were not familiar with the term action research. After knowing meaning of the term, the faculty members discussed their rich experiences about it. The researcher collected data by formal group interviews of sample members of each college. In some cases individual interviews were conducted as the faculty members were not available at a time.

\section{Results}

Present study was conducted to explore awareness of college teachers about action research. It was to find out its practical implementation in the class rooms, moreover this study aims at knowing whether use of action research helps in providing quality teaching and quality learning.

Objective no. 1: To explore teacher's awareness about concept of action research.

Research Question no. 1: What are teachers'views about concept of action research?

\begin{tabular}{|c|c|c|c|}
\hline \multicolumn{4}{|c|}{ No. of Faculty } \\
\hline members & Designation & Experience & Opinion \\
\hline 20 & Lecturer & $3-5$ years & $\begin{array}{l}\text { They are not familiar with technical name of action Research. They are } \\
\text { aware about action research. }\end{array}$ \\
\hline 10 & Assistant Professor & $15-19$ years & $\begin{array}{l}\text { AP depicts that they are also aware about action research. They are } \\
\text { unaware of technical name of action research. }\end{array}$ \\
\hline 05 & Associate Professor & $20-25$ years & They were familiar with action research \\
\hline 05 & Professor & above 25 years & $\begin{array}{l}\text { They expressed their views about action research that its a familiar } \\
\text { domain for them as a teacher. }\end{array}$ \\
\hline
\end{tabular}


The above table shows ground realities that college level teacher is playing very important role for producing desired skilled manpower for the society. Therefore it is very important that concerned departments show interest in training of faculty members so that they will be able to use action research consciously in order to solve problems of the students. Only then it will be possible to meet the challenges of this century and will be able to prepare a futuristic generation. Teacher training programs must address action research and its use in class room by the teachers so that all problems will be addressed on the spot and teacher skill will find out its solution. In this way a reform process can start in the field of education at college level.

All faculty members were agreed that they are using action research practically in the class room from the beginning of teaching till now, as teaching is not possible without solution of problems immediately in the class room.

Objective 02: To find out how teachers use action research for quality instruction. Research Question 02: How action research conducted by teachers effect instruction?

\begin{tabular}{cccc}
\hline Members & Designation & Experience & \\
\hline 20 & Lecture & $3-5$ years & They use action research for solution of problems of students. \\
10 & Assistant Professor & $15-19$ years & $\begin{array}{l}\text { They described that their teaching has important aspect of } \\
\text { solution of problems of students. }\end{array}$ \\
05 & Associate Professor & 20-25 Years & $\begin{array}{l}\text { They admitted that they use action research for immediate } \\
\text { solutions of problems of the students. } \\
\text { They mentioned that teaching is basically to solve problems of } \\
\text { The }\end{array}$ \\
\hline
\end{tabular}

\section{Discussion}

Every member of the sample shared their previews experiences of class room instruction and added examples where they used action research and got the solution of the problem. Experienced fellows were more enthusiastic for sharing their experiences. They told that major areas of problems were comprehension of terminologies for the college students as they were not familiar with then at school level and these subjects of college level are totally new for them. One more problem which they discuss was student lack confidence and they are unable to ask or answer any question in the class room. In this way they are not able to clarify their concepts, with vague concepts they are not able to defend their degrees in future and also not able to utilize those concepts when they need in daily life. According to language teachers students are weak in reading text, so here they used text reading practice and modeling in order to make them proficient in reading, sometimes peer reading activity is also used.

Faculty members of college level were in view that they face problems in planning, instruction, evaluation and class room management every day, sometimes these problems are not addressed timely and sometimes they are handled illogically as faculty members lack coordination in this regard. Professor level staff members suggested that faculty should work as a team for applying action research in this results can be better than ever. The manager of the college can play a vital role in this regard, if she or head of departments conduct meetings among staff members to share problems of the students and hunt for the solutions, experienced faculty can play a role of mentor for the beginners.
Rural area faculty members shown their concern that they are also facing many problems in the class room teaching and learning, they reflect and want to address the problems immediately but they cannot do that mostly. The reason which they provided was that they have shortage of faculty in their colleges and sometimes they are forced to teach another subject which is not their area, in these type of classes teacher reflect and find out the problem but is unable to solve as her knowledge, skill and attitude does not match with the subject. In rural area colleges strength of the students is far more than standard strength in the class rooms. In this situation a teacher is not able to focus on each and every individual student in the class room as they have to complete the syllabus in time as well. Here teacher mentioned that they are addressing group problems and are not able to go for individual one. Urban area faculty members mentioned that students with diverse needs are in their class rooms and they have diverse type of activities and their attention is captured by the advance technology. They do not pay attention to a teacher who is lecturing of discussion. They want multimedia class rooms as their general set up of mind is set with technology. In simple class rooms where teacher and text book is available, student does not take interest and create discipline problems. Sometimes students do not attend classes as they label them boring places. Here teacher is unable to solve these type of problems and higher authorities must be involved in making class rooms better places to learn in for this advance technological generation, moreover teachers should be trained to use this technology for educational purposes.

- Students become valid and strong.

- They become more energetic and motivated towards their profession. 
- They are satisfied with their task and meet their ends.

- They are successful to bring positive behavioral change among students.

- They spent more time in planning.

- They use appropriate methods and techniques for instruction and evaluation.

- They become democratic in nature and give due space to the students.

- Student's academic achievements are now better.

- $\quad$ Faculty members become able to utilize maximum available resources for the teaching and learning process.

- $\quad$ Teaching is no more a teacher centered activity, it becomes problem centered activity.

- Disruptive behavior of the student is controlled as every student is given due time and space.

By analyzing above given points from the faculty members of the colleges, researcher believe that teachers are not only familiar with action research but they are utilizing it in their class rooms for better teaching and learning. This is also a fact that faculty members were not aware about the fact that whatever they are doing in their class rooms from last many years of their service is called action research, and they never ponder over that by using this technique in the class room a major difference occur in learning of the students. This project discussion compel them to reflect on their teaching practices and give this practice a name called action research and become more formal inquiry agents now in the class rooms. Before this discussion faculty members were unconscious researchers in class room but now they will use action research consciously and researcher suppose that now their practice will be more organized and result oriented.

The researcher added in their discussion that teachers using following techniques in their class rooms during instruction but they are not familiar with technical names of these techniques:

Critical inquiry, modeling, collaboration, time for practice, posing questions, giving explanation, re-teaching, exemplification, addressing student individual needs, team work, text reading, think-aloud, compare and contrast, motivational techniques, study of related books, use of self study model, and reflection.

By analyzing these given techniques which are summarized and technically named by the researcher from discussion material are those techniques if used in class rooms can bring a major difference in product of educational institutions?

\section{Suggestions}

Present study was conducted in female colleges of public sector, analysis of given data opened new horizons of thought for the researcher. Keeping in view the facts gathered from field, the researcher suggest following steps to be taken to make colleges a better place to learn in:

- Faculty members are using action research as an unconscious activity, it is informal in nature, they should be provided training in this regard. When they will use action research in formal way as critical inquiry, they will be more focused and results of this effort will be more genuine than ever.

- Faculty members are using this approach individually, but teaching is no more and individual activity, students attending 5-6 classes daily are concern of 5-6 teachers, if one is using action research and other is not using it, difference in student learning will not be obvious. So collaboration among staff members teaching same students is required.

- Experienced staff members are very rich in this regard. They reflected even their first year of teaching and shared their problems and how they handled them. If senior faculty members work as mentors of beginners an institute level training will be possible in less resources and quality time will be utilizes effectively.

- In this era of technology classes are boring places for students and teachers. Teachers need knowledge, skills and techniques for progress in teaching are available in form of technological devices, so technology related to teaching should be provided to faculty members.

- Area of educational psychology is weak of most of the faculty members so they should be trained in this specific area.

- This study was general in nature, further research studies can be conducted on action research by selecting one domain of teaching like cognitive, affective or behavioral and deep observational study can be conducted.

\section{References}

[1] Miller, Christine A. "Action Research: Making Sense of Data." On-line article recovered 11/05/2007

[2] Stevenson, Understanding Action Research, Faculty Advisor, May, 2003 www.coe.fau.edu/sfcel/sensdata.htm.

[3] Carrie Eunyoung Hong, William Paterson University, Salika A. Lawrence, William Paterson University,Action Research in Teacher Education: Classroom Inquiry, Reflection,and Data-Driven Decision Making,2011

[4] Anna Uhl Chamot, Sarah Barnhardt, Susan Dirstine, CONDUCTING ACTION RESEARCH IN THE FOREIGN LANGUAGE CLASSROOM, Northeast Conference 1998,New York, NY,Anna 